\title{
Promoting mental health first aid literacy in secondary schools
}

\author{
Emeritus Professor Alan Glasper, from the University of Southampton, discusses a new initiative designed to \\ help teachers in secondary schools better understand and identify mental health issues in children
}

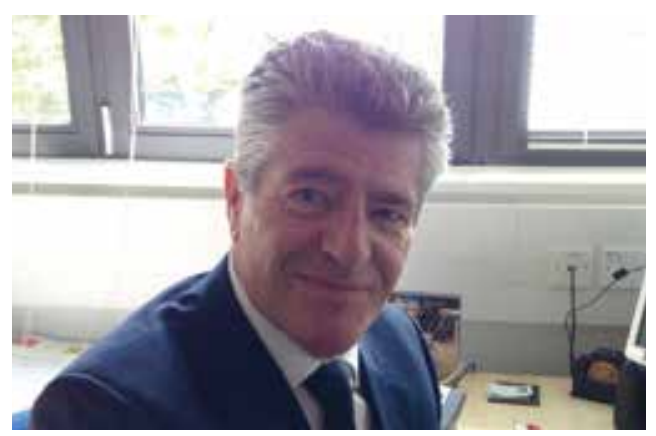

I

n June 2017, as part of its strategy to reform mental health services, the Government announced that it was allocating $\mathcal{E}_{200} 000$ to help teachers understand and identify mental health issues in children through a training programme (Department of Health (DH) et al, 2017).

Every secondary school in England will be offered the training, as part of a Government strategy to transform mental health support for children and young people. The programme will be provided by the social enterprise Mental Health First Aid England (MHFA) and will initially offer training to 1000 teachers (MHFA, 2017a).

There are plans to extend the scheme over the next 2 years to ensure that trained people are in place in every secondary school in England. After training, staff should be able to respond to and manage mental health problems that present in children. These include depression and anxiety, suicidal thoughts, psychosis, self-harm, and eating disorders.

Members of the Royal family have recently backed initiatives to address mental health issues. For example, Prince Harry has warned about the negative effects that excessive mobile phone use has on young people's mental health (Sulleyman, 2017).

Schools have reported that an increasing numbers of pupils are suffering mental ill health and that teachers have found it difficult to get them appropriate support (Pells, 2017).

\section{Mental health in schools}

Emotional problems in childhood are increasingly a cause for concern. The results of a survey of 2000 teachers carried out by The National Association of Schoolmasters and Union of Women Teachers (NASUWT), published in April 2017, showed that:

- Some $98 \%$ of teachers have come into contact with pupils who they believe are experiencing mental health problems

- 91\% were aware of children experiencing anxiety or panic attacks, with $79 \%$ believing that some of their pupils were suffering from depression, $64 \%$ were seeing selfharming children, $49 \%$ were aware of children with eating disorders and $47 \%$ had witnessed pupils with obsessive compulsive disorders, all across a range of ages including children younger than four

- $89 \%$ of teachers reported that mental health issues in children were the cause of poor concentration in lessons

- $91 \%$ of the teachers surveyed believed that family problems at home were creating or contributing to pupils' mental health issues, with $72 \%$ of teachers citing social media pressures as causative and 55\% the impact on children of family poverty or financial worries

- Only $24 \%$ of surveyed teachers said they were confident they would be able to get timely support from expert services such as Child and Adolescent Mental Health Services (CAMHS)

- Some $46 \%$ of respondents stated that they have never received any training on children's mental health (NASUWT, 2017). Despite the prevalence of mental health problems in childhood, many teachers lack the skills to facilitate early intervention. However, teachers are well placed to be able to help children in emotional distress and this new initiative to teach them mental health first aid skills is to be welcomed.

Members of the public, including many employees in a wide variety of occupations, are taught how to manage minor and major physical health emergencies, including basic life support, using a defibrillator and recognising the early signs of a stroke.

Despite the emphasis on learning physical health signs and symptoms, Jorm (2012) highlighted that public awareness of mental health is significantly less well developed.

\section{First aid for mental health}

The MHFA programme was first developed in Australia, and Kitchener and Jorm (2008) have described the development of this enterprise and its subsequent exportation to other countries. They believe that the concept of first aid by the public for physical health crises can be replicated in mental health to facilitate early intervention during a mental health crisis. Mental health first aid training can be delivered in a variety of ways and Jorm et al (2010) have shown how an e-learning programme successfully increased aspects of knowledge about mental health and reduced stigma.

Using statistics from the charity Childline and Public Health England, MHFA states that $10 \%$ of children and young people will have experienced a mental health issue and 20000 contact Childline annually with suicidal thoughts, a figure which has doubled over the past 5 years (MHFA, 2017b). In an average school class of 30 pupils aged 15, a third will have experienced parental separation and one the death of a parent, a fifth will be selfharming and seven of the children will have experienced bullying. With $50 \%$ of all mental health conditions emerging in people before the age of 14 , the role of the teacher may be pivotal in facilitating early intervention and providing pupils with vital support.

The MHFA 1-day training course aims to give teachers practical advice to help them identify and respond to early signs of mental health issues in children and to understand 
the issues their students might face, such as depression and anxiety, self-harm and eating disorders. Teachers who successfully complete the training programme will be invited to become Youth Mental Health First Aid Champions to foster a sharing of knowledge and a greater understanding of mental health issues across their school and the wider community. This training should lead to greater numbers of children receiving more timely and sensitive support to help them cope with mental health issues and help teachers to offer initial support until appropriate professional help is available or until the issue improves.

\section{Children in hospital}

Many nurses work in hospitals where there is school provision for hospitalised children. Hospital schools for sick children aim to lessen, as far as medical circumstances permit, the interruption and disruption to children's and young people's education while they are receiving treatment in hospital so that their academic progress and learning can continue. Hospital school teachers work closely with nursing staff.

When the Care Quality Commission (CQC) conducts inspections of children and young people's services in NHS trusts, inspectors routinely interview the teachers as part of their inspection process. During these inspections the CQC will review any Ofsted reports available.

For example, the 2014 Ofsted report for the school at Great Ormond Street Hospital for Children (GOSH) showed that children with disabilities and those with special educational needs received appropriate levels of support to ensure they were able to achieve as well as other children in the hospital and that those with more complex needs or profound learning difficulties were fully supported by specialist staff. The school received an 'outstanding' Ofsted grade (GOSH, 2014)

It is often the case that hospital school teachers act as additional eyes and ears for the nurses, who are providing complex levels of physical care. Children and young people in a different care environment such as a hospital school may reveal issues pertinent $\Xi$ to their mental health that might not have emerged during a routine admission assessment, especially when the prevailing issue is of a physical nature. It is in these circumstances that the value of multiprofessional team working can be fully appreciated.

\section{Discussion}

Teachers not only have a unique perspective on how individual students are performing academically, but are also well placed to observe how they are emotionally, and it is this aspect of a teacher's role that the Government intends to make more robust. However, it is clear that some teachers of students with emotional and behavioural disorders are at risk of stress and burnout (Nelson et al, 2001), with reports suggesting that many teachers believe that their own mental health has suffered as a result of work pressures (Sellen, 2016).This may be attributed to their inability to successfully manage classroom disruption caused by students with behavioural problems precipitated by mental ill health. Research by the charity Stemming Teenage Mental Illness (STEM4) (http://www.stem4.org. $\mathrm{uk} /$ ), suggests that teachers do not have the necessary skills to help students when they experience emotional distress (Ellis, 2017).

The MHFA initiative, while laudable, is predicated on teachers' ability to refer at-risk children to health professionals at CAMHS. However, CAMHS are already overstretched, with the Health Secretary publicly acknowledging that NHS care of children and young people with mental health issues is inadequate (Campbell, 2016).

Furthermore, the current shortfalls in tier 4 provision, which aspires to meet the care needs of children and young people with the most complex, severe or persistent mental health problems, have been highlighted by McDougall et al (2008).

\section{Conclusion}

Nurses will be reassured by this new initiative to offer mental health first aid training to teachers. Not only will this training improve the mental health literacy of school staff, but it will help them develop the skills to support their students when they are in emotional distress and foster a culture of prompt referral to CAMHS as appropriate. BJN

Campbell D. Jeremy Hunt says child mental health services are NHS's biggest failing. The Guardian. 20 October 2016. http://tinyurl.com/h5c96es (accessed 11 August 2017)

Department of Health, Department for Education, Hun J. Secondary school staff get mental health 'first aid' training. 27 June 2017. https://tinyurl.com/y9mmrjo4 (accessed 11 August 2017)

Ellis R. Mental health problems rife among teenagers but teachers lack skills to help. The Guardian. 26 March 2017. http://tinyurl.com/ku6p3rw (accessed 11 August 2017)

Great Ormond Street Hospital for Children. The Children's Hospital School at GOSH and UCH celebrates outstanding Ofsted report. 2014; 19 March. http:// tinyurl.com/yayqfu3a (accessed 11 August 2017)

\section{KEY POINTS}

- In June 2017 the Department of Health and Department for Education launched an initiative to help secondary school teachers better understand and identify mental health issues in children

v $£ 200000$ in funding has been promised to deliver Mental Health First Aid programmes to teachers

- Up to $10 \%$ of children are believed to have a diagnosable mental health disorder, with half of all mental health conditions beginning before the age of 14

- Many schools report that there has been an increase in the number of children suffering from mental health issues and that teachers are struggling to access appropriate support

- The initiative to give teachers training relies on their timely ability to refer students to Child and Adolescent Mental Health Services (CAMHS), which are already overstretched

Jorm AF. Mental health literacy: empowering the community to take action for better mental health. Am Psychol. 2012; 67(3):231-243. https://doi.org/10.1037/a0025957

Jorm AF, Kitchener BA, Fischer J-A, Cvetkovski S. Mental health first aid training by e-learning: a randomized controlled trial. Aust N Z J Psychiatry. 2010; 44(12):10721081. https://doi.org/10.3109/00048674.2010.516426

Kitchener BA, Jorm AF. Mental Health First Aid: an international programme for early intervention. Early Interv Psychiatry. 2008; 2(1):55-61. https://doi. org/10.1111/j.1751-7893.2007.00056.x

McDougall T, Worrall-Davies A, Hewson L, Richardson G, Cotgrove A. Tier 4 Child and Adolescent Mental Health Services (CAMHS): inpatient care, day services and alternatives: an overview of Tier 4 CAMHS provision in the UK. Child and Adolescent Health 2008; 13(4):173180. https://doi.org/10.1111/j.1475-3588.2007.00481.x

Mental Health First Aid England.Youth MHFA in schools programme. 2017a. http://tinyurl.com/ycdtgoej (accessed 11 August 2017)

Mental Health First Aid England.Youth MHFA in schools social media toolkit. 2017b. http://tinyurl.com/ya78z7zr (accessed 11 August 2017)

National Association of Schoolmasters and Union of Women Teachers. Schools need support to deal with mental health upsurge among pupils. 2017; 5 July http://tinyurl. com/yaanzcsq (accessed 11 August 2017)

Nelson JR, Maculan A, Roberts ML, Ohlund BJ. Sources of occupational stress for teachers of students with emotional and behavioral disorders. Journal of Emotional and Behavioral Disorders. 2001; 9(2): 123-130. https:// doi.org/10.1177/106342660100900207

Pells R. Four-year-olds suffering panic attacks, eating disorders, anxiety and depression, report says. Independent. 2017; 14 April. http://tinyurl.com/ mht6vmg (accessed 11 August 2017)

Sellen P. Long hours and low pay: why England's teachers face burnout. The Guardian. 2016; 11 October. http:// tinyurl.com/yd4tpwj5 (accessed 11 August 2017) Sulleyman A. Prince Harry warns young people against excessive phone use in speech about mental health. Independent 2017; 7 July. http://tinyurl.com/y8ba4r4v (accessed 11 August 2017) 